\title{
AUGUSTO FRANCO: CRÍTICA E POLÊMICA
}

Luiz Antônio Paganini*

RESUMO:

Estudo dos textos do crítico e polemista Augusto Franco, revelando a sua concepção de literatura e de crítica, as características de suas análises literárias, as suas participações em certas polêmicas e a recepção crítica desses mesmos textos.

PALAVRAS-CHAVES: crítica, polêmicas, jornalismo, recepção.

Augusto Fidelis Franco nasceu em 1877, em uma localidade chamada, à época, Quilombo, depois denominada União, distrito de Barbacena, e que, atualmente, constitui o município de Bias Fortes. Em Barbacena, ele principiou a colaborar na imprensa local e, ao mudar-se para Juiz de Fora, deu continuidade ao trabalho jornalístico, escrevendo para o Correio de Minas e atuando como redator-secretário do Jornal do Comércio, ambos desta última cidade.

Em 1899, publicou o seu primeiro livro, Ensaios literários, caracterizado por uma face ficcional e outra crítica. Porém, logo deixou de escrever ficção, passando a dedicar-se à pratica do jornalismo opinativo e aos ensaios críticos. Algum tempo depois, a convite de Antônio Carlos Ribeiro de Andrada, mudou-se para Belo Horizonte, onde passou a trabalhar no Diário de Minas e, a seguir, no Minas Gerais. Entre 1900 e 1906, publicou os seguintes livros e opúsculos: Antônio Sales: perfil bio-literário (1900), Estudos ligeiros: sobre um livro de crítica (1900), Linhas de crítica: apreciações e polêmicas (1900), Breve resposta (ao Sr. Laudelino Freire) (1903), Fragmentos literários: crônicas ligeiras (1904), Dr. João Pinheiro: ensaio biográfico e político (1905 e 1906), Três estudos (1905), Defesa pessoal: aos que me não conhecem (1906) e Estudos e escritos: esboços e crônicas (1906). Em 1904, atuou como editor do opúsculo Passe recibo, de Sílvio Romero, texto que fazia parte de uma polêmica do crítico sergipano com o historiador português Teófilo Braga.

* Mestre em Letras: Estudos Literários (Área de concentração: Teoria da Literatura), 2000. 


\section{EM TESE}

Belo Horizonte, v. 5, p. I-305, dez. 2002

Outros fatos de sua biografia merecem ser ressaltados nesse periodo: a direção do jornal Vida Mineira até o número 14 - a partir daí, ele continuou participando no jornal apenas como colaborador (1904-1906); a organização de uma exposição do pintor A. Delpino, juntamente com Noronha Guarany e Mário de Lima, em 1906; a direção da Imprensa Oficial de Minas Gerais em 1906 e a participação num dos mais importantes panoramas da literatura brasileira da Belle Époque, as entrevistas de 0 momento literário, de João do Rio, publicadas no jornal Gazeta de Notícias entre 1904 e 1905, mais tarde reunidas em livro (1907). Sua última obra, Direito e economia, foi publicada em forma de opúsculo também em 1907.

Entre 1907 e 1908, viajou para a Alemanha, onde foi ampliar os seus estudos e buscar tratamentos mais modernos para uma grave moléstia. Apesar de seus esforços, veio a falecer, aos 32 anos, em 11 de setembro de 1909, na cidade de Freiburg, Grão Ducado de Baden.

Ao fazer jornalismo de opinião e publicar livros, Franco escreveu ou apenas se responsabilizou, como editor, por algumas formas de ensaio, que, segundo a classificação de Marc Angenot, podem ser enquadradas na categoria dos discursos agônicos. (Angenot, 1982: 34). Uma parte dessa produção poderia ser considerada como crítica e outra como polêmica. Esses textos, seguindo a orientação evolucionista, o colocam entre os epígonos da Escola do Recife. De fato, Augusto Franco foi um representante das idéias defendidas pelos autores nordestinos em uma região dominada pelo positivismo comtiano. Naquele momento, Minas recebia muito bem as idéias positivistas que os bacharéis formados na Academia de Direito de São Paulo traziam. Augusto Franco fazia parte do pequeno grupo que, reunido em torno de Sílvio Romero, tentava fazer proselitismo da Escola do Recife na região Sudeste. 0 grupo era formado, além de Graça Aranha e de Fausto Cardoso, por vários estudiosos, como Artur Guimarães, Tito Lívio de Castro, Samuel de 0liveira e alguns outros. (Paim, 1966: 79-81). Uma prova da consideração que Sílvio Romero demonstrava pelo crítico mineiro foi a sua inclusão na lista dos autores nacionais que produziram estudos sobre a literatura brasileira, no primeiro capítulo de sua História da literatura brasileira, ao lado de Araripe Júnior, Machado de Assis, José de Alencar, José Veríssimo, Artur Orlando, entre outros. (Romero, 1980: 53). 
No contexto mineiro, ao lado de resenhas apenas apologéticas ou censuras ferozes sem nenhuma preocupação teórica, Augusto Franco tentava fundamentar as suas análises, esboçando um projeto de crítica científica. Do mesmo modo que outros críticos brasileiros ligados ao movimento de idéias surgido na década de 1870, Franco tentou estabelecer o seu conceito de crítica em consonância com um determinado conceito de literatura. Mas as dificuldades desse projeto, o qual pressupunha uma reflexão metodicamente orientada e um conhecimento profundo no campo dos estudos literários, não o impediram de realizar a tentativa, buscando conjugar concepções teóricas diversas.

Augusto Franco empregava o termo literatura com um sentido bem amplo. A adoção desta concepção não provinha de um desconhecimento do sentido estrito do termo literatura, mas era, ao contrário, uma escolha deliberada. Neste ponto e em outros, ele se aproximava de seu mestre Sílvio Romero. Mas apesar disso, o crítico mineiro não era um simples repetidor do autor nordestino. Um traço distintivo de Franco pode ser encontrado no seu conceito de crítica, que ele esboçou em vários textos, principalmente os da sua primeira fase (aquela na qual escrevia resenhas literárias), e buscou definir em um de seus ensaios publicados no livro Fragmentos literários.

Após uma observação da crítica realizada na sua época, que pretendia ser científica, Augusto Franco chegou à classificação de três tipos de análise ou "processos de crítica", como ele os nomeava. 0 primeiro era o sociológico, o segundo, o psicológico e o terceiro, o estético. Em todos eles, o crítico poderia se valer das contribuições das "ciências conexas ou afins ao processo". (Franco, 1904: 204), ou seja, exercer uma prática interdisciplinar avant la lettre. Franco mencionou ainda que, para certos pensadores, haveria um quarto tipo de análise crítica: a estopsicologia - referência à teoria de Émile Hennequin (1858-1888). Mas ele duvidava da exeqüibilidade desse último tipo, talvez pelo fato dessa leitura englobar as três modalidades referidas acima. Entre os três "processos de crítica", para Augusto Franco, o que mais se destacava era o sociológico e, entre os autores que o exerciam, Taine era o mais notável. Deste crítico, ele aceitou a doutrina dos três fatores que influem sobre a obra literária: a raça, o momento e o meio. Mas ele 


\section{EM TESE}

Belo Horizonte, v. 5, p. I-305, dez. 2002

enfatizava o papel da hereditariedade e da seleção natural na causação dos fenômenos culturais. Segundo Franco, essa doutrina seria especialmente adequada para os estudos históricos.

0 segundo tipo de análise crítica, o psicológico, consistiria em uma reflexão sobre o "estado d'alma do escritor e dos consumidores dos seus produtos literários". (Franco, 1904: 208). Já a crítica estética, no caso da literatura, visa estudar as emoções despertadas no leitor pelo efeito do belo. Para Augusto Franco, a apreciação estética tem uma dupla face, dependendo do "agente e do legente, isto é, de quem produz e de quem 1ê". (Franco, 1904: 208). Neste ponto de vista, a percepção estética passa a ser vista de uma forma relativa, dependendo do sujeito que entra em contato com a obra. Por isso, a beleza de certos textos não pode ser notada por determinados leitores. À crítica estética cabe, então, a tarefa de estudar o motivo do sucesso ou do insucesso da obra. (Franco, 1904: 208).

De acordo com o crítico mineiro, o estudo dos aspectos sociais está sempre em jogo tanto na crítica psicológica quanto na estética e é por isso que ele achava a análise sociológica superior às outras duas. (Franco, 1904: 209).

Confrontemos estas idéias com as de Sílvio Romero e vejamos o que as distingue. Em Romero, notamos facilmente um desprezo pela abordagem estética da obra literária (a preocupação com os aspectos internos da obra era considerada uma sobrevivência da retórica e da metafísica) e uma modificação nos critérios de avaliação, que passam a ser culturais. Como bem mostrou Roberto Ventura, o valor das obras e dos escritores tornou-se dependente de sua "representatividade nacionalística e etnográfica", de seu papel na "evolução cultural". (Ventura, 1991: 111). Encontramos aqui um dos pontos que diferenciam Augusto Franco de Sílvio Romero. Ao contrário deste, Franco não revelou falta de apreço pela abordagem estética (ele a considerava um dos tipos possíveis de leitura crítica). Nas leituras que ele realizou, os aspectos formais (questões de estilo e de linguagem) não foram deixados de lado. Para Augusto Franco, a leitura deve ser uma análise minuciosa das partes componentes do livro/texto: "o estilo, a linguagem, as descrições, o espírito de observação, o modo de tratar os assuntos, a correção gramatical, a pintura dos quadros, 0 conjunto, finalmente, para daí tirar a soma favorável ou não ao autor ou autora". 
(Franco, 1900: 96-97). Também não pensava a crítica, no sentido que o termo ganhou no ensaio Da crítica e sua exata definição, de Sílvio Romero. Neste texto, a crítica era entendida como uma parte da lógica e o estudo de um texto literário, no sentido estrito, era pensado como um trabalho de estética e não de crítica. (Romero, 1980: 342).

No exercício crítico, Augusto Franco revelou predileção pelos textos que possuíam imagens claras, descrições "perfeitas", frases harmônicas e precisão dos termos. Valorizava sobremaneira a clareza da expressão, a linguagem facilmente compreensível, indicando uma enorme preocupação com a legibilidade dos textos e com a representação do real. Embora houvesse reprovado os autores com a "mania da gramatiquice" e com obsessão pelo estilo, ele não desmereceu a observância da gramática e da estilística nas suas análises. Para Franco, ambos tinham uma grande importância na crítica psicológica, no que se refere à caracterização do temperamento, do estado de alma do escritor. Encontramos dois exemplos deste tipo de análise no opúsculo Breve resposta e na resenha do livro Música sacra, do poeta gaúcho Mário Artagão.

Uma característica da crítica de Augusto Franco foi o multilingüismo (uso de várias línguas nos seus textos: francês, latim, italiano, alemão). Especialmente interessante é o seu germanismo, que se manifestava como um mosaico de citações e de referências bibliográficas alemãs. Para nós, tal germanismo poderia ser visto como a demonstração da posse de um conhecimento raro, prova de atualização cultural ou forma de integração no seio da Escola do Recife. Mas a característica mais marcante das avaliações realizadas pelo crítico mineiro é, certamente, o seu polemismo. Ele admirava os críticos que, como Zola, abordavam os assuntos de modo violento. 0 crítico deveria sempre lutar pelas suas idéias. Neste ponto, a concepção de crítica defendida por Franco se assemelha àquela de Sílvio Romero: tanto a polêmica quanto a crítica eram pensadas como duas faces do "espírito especulativo". A crítica de Augusto Franco acabou por ser contaminada pelo seu polemismo. 0 tom dominante nos seus ensaios era o agressivo e a abordagem dos textos era severa. Em muitas das críticas escritas por Franco, encontramos os mesmos procedimentos empregados nas suas polêmicas. Por isso, poderíamos dizer que ele tinha um estilo combativo, ou, um stilus pugnax. Augusto Franco estava sempre envolvido em conflitos nos quais tentava vencer e eliminar as idéias que considerava errôneas. No nível simbólico, 


\section{EM TESE}

Belo Horizonte, v. 5, p. I-305, dez. 2002

uma polêmica representaria a luta pela vida e a participação nessas disputas teria o mérito de favorecer a evolução cultural do país, num processo análogo ao de seleção natural, onde o mais forte, ao vencer o mais fraco, aperfeiçoa a espécie.

Uma polêmica pode desencadear outras polêmicas com outros participantes, o que configura um tipo de rede em que vários textos polêmicos se defrontam. Augusto Franco, por exemplo, acabou participando ativamente de duas polêmicas de Sílvio Romero: uma contra o historiador e crítico português Teófilo Braga e o seu defensor Fran Paxeco e, a outra, contra o jovem crítico Laudelino Freire. A primeira contenda começou com a reação de Sílvio Romero contra o autor da introdução e notas da edição portuguesa dos Cantos populares do Brasil e dos Contos populares do Brasil, Teófilo Braga. 0 crítico nordestino o acusou de plágio e deturpação dos textos originais no opúsculo Uma esperteza.

De acordo com Roberto Ventura, Augusto Franco começou a sua participação na polêmica quando rebateu o livro do português Fran Paxeco, que veio em defesa de Braga. (Ventura, 1991: 174). 0 livro de Paxeco, intitulado 0 sr. Sílvio Romero e a literatura portuguesa (1900), trazia uma carta de Braga na qual este respondia às acusações que The eram feitas. A réplica de Romero veio no opúsculo Passe recibo réplica à Teófilo Braga (1904), publicado em Belo Horizonte, na Imprensa Oficial de Minas Gerais, por intermédio de Augusto Franco. É preciso salientar que se trata da edição de um dos textos fundamentais da polêmica entre Sílvio Romero e Teófilo Braga. Em uma época repleta de dificuldades para os escritores publicarem os seus textos, Franco empenhou-se bastante para apresentar ao público o trabalho de Romero. Além disso, o crítico mineiro foi o autor do prefácio, do posfácio e de algumas notas do referido opúsculo, no qual defendeu fortemente o seu mestre, exaltando-o com um fervor quase religioso. Esses textos de Augusto Franco visavam não somente a defesa de Romero, mas também a dos intelectuais brasileiros, especialmente os naturalistas. Significavam uma defesa da literatura nacional contra os ataques lusitanos.

A segunda contenda, começou com a publicação do livro Sílvio Romero: página de crítica impressionista, de Laudelino Freire, em 1900. Nessa obra, Freire pretendia realizar um estudo da "personalidade literária" do crítico e historiador sergipano. Ele avaliou a História da literatura brasileira de forma ambígua, ora 
elogiando-a, ora fustigando-a. O Sîlvio Romero crítico, ao contrário do historiador, só recebeu censuras.

Sîlvio Romero não respondeu imediatamente às acusações de Freire, mas somente quatorze anos depois. Naquela época, quem entrou na arena foi Augusto Franco com o opúsculo Estudos ligeiros (1900). No ano seguinte, Laudelino Freire respondeu com o livrete Linhas de polêmica. Em 1903, Franco deu continuidade à contenda, publicando Breve resposta (ao Sr. Laudelino Freire). Tanto Augusto Franco quanto Laudelino Freire adotavam uma manipulação dos textos com a finalidade de conduzir os receptores da contenda a tomar partido contrário ao do adversário. Ambos competiam pela sedução/ilusão dos leitores, não apenas através de provas racionais. As estruturas textuais desses opúsculos e livros possibilitavam uma oscilação entre dois tipos de leitura: uma de primeiro grau, que podia satisfazer grande parte dos leitores daquela época. Leitores com baixa instrução e interesses mais voltados para o divertimento (a polêmica também era diversão), e outra, de segundo grau, que visava um público mais intelectualizado, preocupado com questões de estilo literário e com teorias diversas. Não é à-toa que coexistem, nos mesmos textos polêmicos, 0 emprego de vituperantes e de ironia, linguagem gíria e termos filosóficos, científicos ou raros, ou ainda, citações de autores estrangeiros no original.

Entre 1904 e 1906, Augusto Franco se envolveu em um conflito entre jornais de Belo Horizonte. De um 1ado, o jornal Vida Mineira, dirigido pelo próprio Franco, e de outro, os jornais A Epocha e 0 Estado de Minas - um homônimo do jornal dos Diários Associados. 0 Vida Mineira não polemizava apenas por questões políticas e a prova disso são as contendas literárias que, nesse órgão de imprensa, encontraram meio de expressão, como a surgida em torno da imagem póstuma de Bernardo Guimarães. Do lado oposto, 0 Estado de Minas era chefiado pelo poeta decadentista Álvaro Vianna e também apresentava uma feição literária, tendo publicado muitos poemas de Alphonsus de Guimaraens e alguns do próprio Álvaro. Neste jornal, Álvaro Vianna continuou o ataque sistemático que já vinha realizando em A Epocha ao governo estadual e a Augusto Franco.

No jogo político de então, Augusto Franco foi tomado como bode expiatório. De um lado, os opositores do governo Francisco Sales tinham necessidade de achar um 


\section{EM TESE}

Belo Horizonte, v. 5, p. I-305, dez. 2002

rosto que encarnasse os aspectos negativos apontados naquela gestão, de outro, 0 próprio governo usou o jornal Vida Mineira para manifestar uma forte reação contra os ataques que vinha sofrendo.

Em relação às funções ideológicas desempenhadas pelo Vida Mineira, a primeira delas foi a defesa do governo. A segunda foi a de combate às idéias políticas que não se adequavam aos projetos das elites dominantes - socialismo, anarquismo - e às idéias literárias que rompiam com a representação realista e os ideais nacionalistas.

Nessa polêmica, houve uma apropriação de elementos caraterísticos da sátira e do panfleto. As conseqüências disso foram que a linguagem empregada tornouse repleta de vituperantes, os textos adquiriram aspectos mais literários, ficcionalizantes, caricaturais e os discursos tenderam para o desprezo pelo adversário.

Podemos perceber uma radical mudança na recepção da obra de Augusto Franco. Os leitores contemporâneos do crítico mineiro (Correia de Almeida, Artur Orlando, França Pereira, Afonso Celso, Leopoldo de Freitas, Wenceslau de Queiroz e Sílvio Romero) valorizaram a "orientação científica ou filosófica" de seus estudos, admiraram o seu espírito combativo, porém reprovaram certos exageros que ele costumava cometer em seus julgamentos. Após a sua morte, Franco sofreu processo de esquecimento devido a uma mudança no horizonte de expectativas (transformações filosóficas e dos padrões literários) e à inexistência de reedições de suas obras. Essa situação só iria se alterar com um ensaio de Eduardo Frieiro em 1951, texto que pode ser considerado um marco na recepção de Augusto Franco, pois desencadeou outras leituras como as de Fábio Lucas, Martins de 0liveira, Wilson Martins, José Carlos Rodrigues e Alexandre Eulálio, produzindo uma quase-lembrança. 
ABSTRACT :

This essay examines texts written by the critic and polemist Augusto Franco showing his conception of literature and criticism. It studies the features of his literary analyses, his participation in some polemics and the critical reception of these writings.

KEY WORDS: criticism, polemics, journalism, reception.

REFERÊNCIAS BIBLIOGRÁFICAS

ANGENOT, Marc. La parole pamphlétaire: typologie des discours modernes. Paris: Payot, 1982.

FRANCO, Augusto. Linhas de crítica. Juiz de Fora: Progresso, 1900. (Microfilme).

- Breve resposta (ao Sr. Laudelino Freire). Belo Horizonte: Imprensa Oficial do Estado de Minas, 1903. - Prefácio, posfácio e notas. In: ROMERo, Sílvio: Passe recibo: réplica a Teófilo Braga. Belo Horizonte: Imprensa Oficial do Estado de Minas Gerais, 1904.

- Três estudos. Lisboa: A Editora, 1905.

- Estudos e escritos: esboços e crônicas. Belo Horizonte: Imprensa Oficial de Minas Gerais, 1906. - Defesa pessoal: aos que me não conhecem. Vida Mineira, Belo Horizonte, 27 abr. 1906, p.1.

- Direito e economia. Belo Horizonte: Imprensa Oficial de Minas Gerais, 1907.

PAIM, Antônio. A filosofia da Escola do Recife. Rio de Janeiro: Saga, 1966.

ROMERO, Sílvio. História da literatura brasileira. 7. ed. Rio de Janeiro: José 01ympio; Brasillia: INL, 1980. v. 1.

VENTURA, Roberto. Estilo tropical: história cultural e polêmicas literárias no Brasil (1870-1914). São Paulo: Companhia das Letras, 1991. 